This is the author's final, peer-reviewed manuscript as accepted for publication. The publisher-formatted version may be available through the publisher's web site or your institution's library.

\title{
Competing hydrogen-bond donors: phenols vs. cyanooximes
}

Christer B. Aakeröy, Kanishka Epa, Safiyyah Forbes, and John Desper

\section{How to cite this manuscript}

If you make reference to this version of the manuscript, use the following information:

Aakeröy , C. B., Epa, K., Forbes, S., \& Desper, J. (2013). Competing hydrogen-bond donors: Phenols vs. cyanooximes. Retrieved from http://krex.ksu.edu

\section{Published Version Information}

Citation: Aakeröy , C. B., Epa, K., Forbes, S., \& Desper, J. (2013). Competing hydrogen-bond donors: Phenols vs. cyanooximes. CrystEngComm, 15(30), 5946-5949.

Copyright: @ The Royal Society of Chemistry 2013

Digital Object Identifier (DOI): doi:10.1039/c3ce41023d

Publisher's Link:

http://pubs.rsc.org/en/Content/ArticleLanding/2013/CE/c3ce41023d\#!divAbstract

This item was retrieved from the K-State Research Exchange (K-REx), the institutional repository of Kansas State University. K-REx is available at http://krex.ksu.edu 


\title{
Competing hydrogen-bond donors: Phenols vs. cyanooximes
}

\author{
Christer B. Aakeröy, ${ }^{\text {a }}$ Kanishka Epa, ${ }^{\text {a }}$ Safiyyah Forbes, ${ }^{\text {a }}$ and John Desper ${ }^{\mathrm{a}}$ \\ Received (in $X X X, X X X) X$ th $X X X X X X X X X 20 X X$, Accepted $X$ th $X X X X X X X X X 20 X X$ \\ DOI: $10.1039 / \mathbf{b 0 0 0 0 0 0 x}$
}

${ }_{5}$ Based on a systematic structural study of co-crystals of a ditopic probe molecule, (Z)-N,4-dihydroxybenzimidoyl cyanide, decorated with an - $\mathrm{OH}$ group and a cyanooxime moiety, it has been shown that in a competitive molecular recognition event, the former is the better hydrogen-bond

${ }_{10}$ donor. This structural behaviour is reflected by calculated electrostatic potential surfaces of the competing donors, which highlights that electrostatic charge can offer a reliable tool for predicting primary hydrogen-bond preferences.

The oxime moiety is a common chemical functionality often 15 found in pharmaceuticals, ${ }^{1,2}$ agrochemicals, ${ }^{3}$ organometallics ${ }^{4}$ and in biological materials. ${ }^{5}$ The structural and bio-physical properties of all oximes are directly related to its hydrogen-bond capability, but what sets it apart from most other donor groups is its tunability ${ }^{6}$ which can be readily affected by altering the 20 substituent $(-\mathrm{X})$ on the carbon atom, Scheme 1.

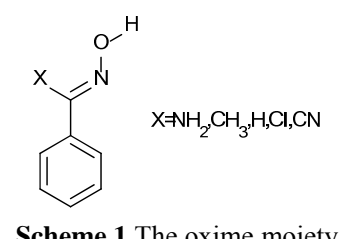

on the same molecular backbone? To address this issue, we 45 synthesized (Z)-N,4-dihydroxybenzimidoyl cyanide as a suitable probe molecule, and co-crystallized it with eight different hydrogen-bond acceptor molecules each equipped with two binding sites of different strength, Scheme 2 .

The ranking of the acceptor sites was established using 50 calculated molecular electrostatic potential (MEP) surfaces. Similar calculations were performed on the $-\mathrm{OH} /$-oxime probe molecule, and the results show that the hydrogen atom of the $\mathrm{OH}$ moiety carries a higher positive charge than the hydrogen atom of the cyanooxime, and is consequently designated as the 55 better hydrogen-bond donor, D1 (the oxime becomes the secondbest donor, D2), Scheme 2.

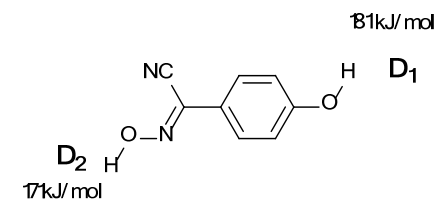

Scheme 2 (Z)-N,4-dihydroxybenzimidoyl cyanide, PhOx

According to best-donor/best acceptor guidelines for molecular ${ }_{60}$ recognition, ${ }^{17}$ we would expect that the better donor should bind to the better acceptor on the ditopic molecules employed herein, Scheme 3 .

Aldoximes and acetyloximes normally form head-to-head dimers in the solid state through a pair of O-H...N interactions. ${ }^{6}$ ${ }_{25}$ However, cyanooximes, ${ }^{7}$ where the oxime nitrogen atom is a particularly weak hydrogen-bond acceptor due to the presence of the electron-withdrawing $-\mathrm{CN}$ moiety, ${ }^{8,9}$ tend to act as a single point hydrogen-bond donors similar to an $-\mathrm{OH}$ group. ${ }^{10}$ The latter functionality is ubiquitous in biological systems, and is also 30 heavily utilized in applications such as templated covalent synthesis, ${ }^{11}$ nonlinear optics ${ }^{12}$ and sensors. ${ }^{13}$ Again, many functions and properties of $-\mathrm{OH}$ substituted molecules are directly related to their hydrogen-bond capabilities.

A key requirement for effective supramolecular synthesis and ${ }_{35}$ crystal engineering, ${ }^{14}$ is a detailed understanding of the structural balance between different synthons, and therefore it is important to establish how potentially competing interactions will manifest themselves in the solid state. It has previously been shown that both cyanooxime moieties ${ }^{15}$ and phenolic $-\mathrm{OH}$ groups ${ }^{16}$ are more 40 effective hydrogen-bond donors than carboxylic acids. The question is, can we establish a reliable ranking of the hydrogenbond efficiency of these two moieties based upon systematic cocrystallizations of a single molecule that contains both moieties
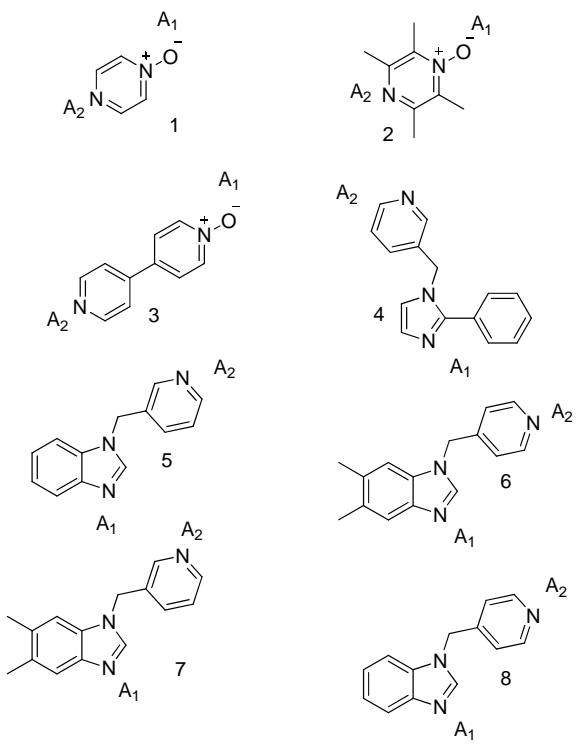

Scheme 3 Eight ditopic acceptors (5-7 were synthesized according to previously published methods. ${ }^{15,18}$ ) 
In each case, $A_{1}$ indicates the stronger acceptor and $A_{2}$ the weaker hydrogen-bond acceptor site based on calculated MEP values.

Table 1 MEP (AM1) values of acceptors 1-8

\begin{tabular}{ccc}
\hline & & \\
Acceptor & $\mathrm{A}_{1} / \mathrm{kJmol}^{-1}$ & $\mathrm{~A}_{2} / \mathrm{kJmol}^{-1}$ \\
\hline $\mathbf{1}$ & -266 & -232 \\
$\mathbf{2}$ & -287 & -255 \\
$\mathbf{3}$ & -294 & -249 \\
$\mathbf{4}$ & -290 & -279 \\
$\mathbf{5}$ & -292 & -262 \\
$\mathbf{6}$ & -301 & -269 \\
$\mathbf{7}$ & -296 & -261 \\
$\mathbf{8}$ & -291 & -268
\end{tabular}

5 The charges bear the units of potential as they are calculated based on the maxima and minima of a calculated molecular electrostatic potential surface which represents the points of highest and lowest charge on the molecule.

10 MEP surfaces were constructed using Spartan '06 (Wavefunction, Inc. Irvine, CA). All molecules were geometry optimized using AM1, with the maxima and minima in the electrostatic potential surface (0.002 $\mathrm{e} \mathrm{au}^{-1}$ isosurface) determined using a positive point charge in vacuum as a probe.

15

Ditopic acceptors 1-8 were co-crystallized with PhOx by combining the relevant reactants in methanol in a $1: 1$ ratio, followed by slow evaporation. Five co-crystals suitable for single crystal X-ray diffraction were obtained.

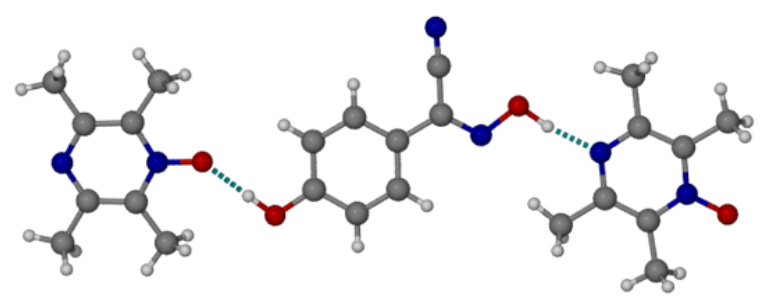

Fig 1 The primary hydrogen bonds in the crystal structure of PhOx:2

The crystal structure determination of PhOx:2 shows that in the resulting 1:1 co-crystal, the best donor, the $-\mathrm{OH}$ moiety, forms a hydrogen bond to the N-oxide oxygen atom, the best

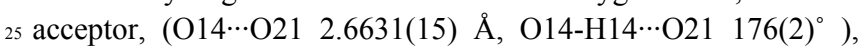
and the second-best donor, cyanooxime, engages in a hydrogen bond with the pyridyl nitrogen atom, the second-best acceptor,

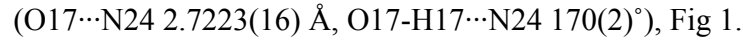

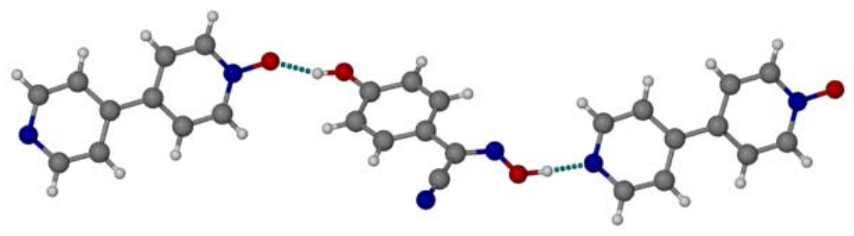

30 Fig 2 The primary hydrogen bonds in the crystal structure of PhOx:3

In the crystal structure of PhOx:3, also a 1:1 co-crystal, the $\mathrm{OH}$ moiety forms a hydrogen bond to the $\mathrm{N}$-oxide oxygen atom, $\left(\mathrm{O} 14 \cdots \mathrm{O} 21 \quad 2.6052(19) \quad \AA, \quad \mathrm{O} 14-\mathrm{H} 14 \cdots \mathrm{O} 21 \quad 163(2)^{\circ}\right)$, and cyanooxime, interacts with the pyridyl nitrogen atom, $(\mathrm{O} 17 \cdots \mathrm{N} 31$ ${ }_{35} 2.665(2), \mathrm{O} 17-\mathrm{H} 17 \cdots \mathrm{N} 31$ 176(2) $)$, Fig 2

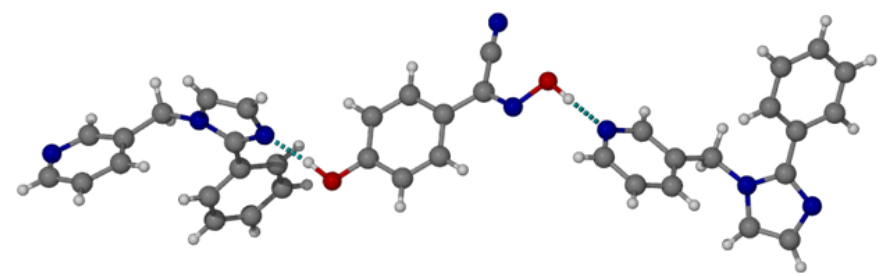

Fig 3 The primary hydrogen bonds in the crystal structure of PhOx:4

The 1:1 co-crystal of PhOx:4 shows that the $-\mathrm{OH}$ moiety of

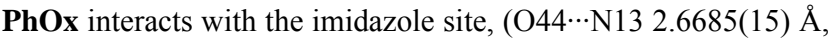
$\left.{ }_{40} \mathrm{O} 44-\mathrm{H} 44 \cdots \mathrm{N} 13169(2)^{\circ}\right)$, leaving D2, the cyanooxime, to form an $\mathrm{O}-\mathrm{H} \cdots \mathrm{N}$ hydrogen bond with the pyridyl nitrogen atom $\left(\mathrm{O} 47 \cdots \mathrm{N} 212.6536(14) \AA, \mathrm{O} 47-\mathrm{H} 47 \cdots \mathrm{N} 21\right.$ 176(2) $\left.{ }^{\circ}\right)$, Fig 3.

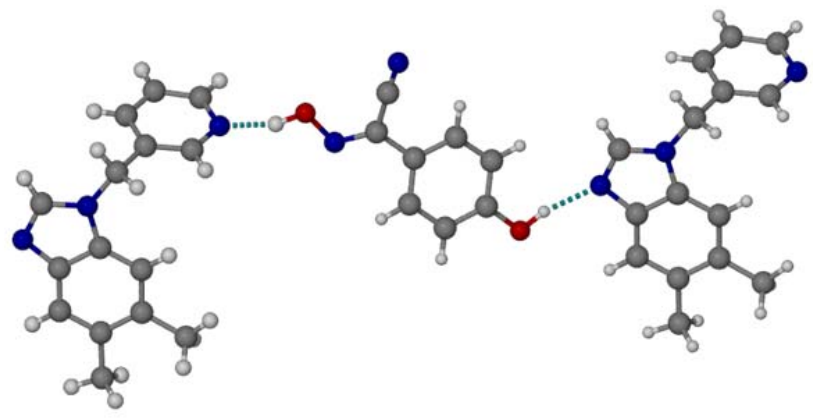

Fig. 4 The primary hydrogen bonds in the crystal structure of PhOx:7

45 The structure determination of PhOx:7 shows that in the resulting 1:1 co-crystal $\mathrm{D} 1$, the $-\mathrm{OH}$ site, binds to $\mathrm{A} 1$, the

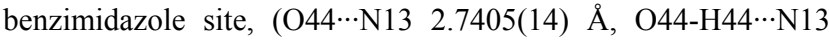

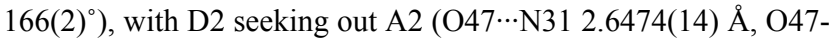
H47 $\cdots \mathrm{N} 31$ 161(2) ${ }^{\circ}$, Fig 4.

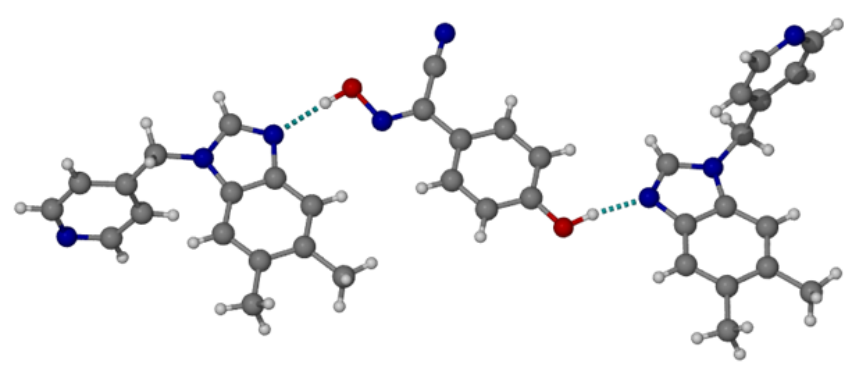

Fig. 5 The primary hydrogen bonds in the crystal structure of PhOx:6

Finally, the crystal structure determination of PhOx:6 produced the only outlier in this series. First, the stoichiometry is unexpected with a PhOx to 6 ratio of 1:2. Second, both donor 55 sites form hydrogen bonds to the better acceptor, the imidazole

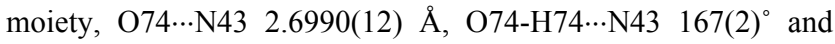

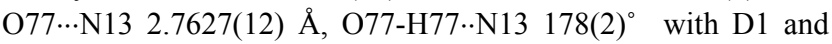
D2, respectively, Fig 5 .

60 The overall picture that emerges from these five crystal structures is that when a hydrogen-bond preference is expressed by the two donors on PhOx (which happens in four of five cases) 
the primary molecular recognition events can be rationalized using a ranking based on MEP surface calculations. Furthermore, in a competition between an aromatic - $\mathrm{OH}$ moiety and a cyanooxime, the former is likely to be more competitive for the 5 best available hydrogen-bond acceptor. The appearance of a 1:2 co-crystal were both D1 and D2 bind to the imidazole moiety on a neighbouring molecule, in preference to the pyridyl moiety, strengthens the argument that charge is the dominating factor driving the formation of hydrogen bonds in a multi-functional 10 system. It could have been argued that the cyanooxime group has an inherent geometric preference for a pyridyl moiety as this type of hydrogen is formed in the first four crystal structures. However, as a cyanooxime $\cdots$ imidazole $\mathrm{O}-\mathrm{H} \cdots \mathrm{N}$ hydrogen bond is present in the crystal structure of PhOx:6, there is nothing to 15 suggest that a geometric bias is responsible for the consistent structural patterns that were found. Furthermore, acceptor 6, which is the only compound that produces a 1:2 co-crystal, carries a charge on its A1 site of $-301 \mathrm{~kJ} / \mathrm{mol}$ which is greater than that found on the corresponding site in any of the other 20 acceptors. This may explain why both donors in PhOx are keen to form hydrogen bonds to the same acceptor in $\mathbf{6}$, resulting in a 1:2 stoichiometry. The calculated $\mathrm{pK}_{\mathrm{a}}$ value of phenylcyanooxime, $7.80^{19}$, is lower than that of phenol, $9.86^{18}$, which underscores that acidities do not provide reliable indicators 25 of relative hydrogen-bond strength when comparing different chemical moieties.

There are no relevant crystal structures in the CSD that can be used to augment the data in this study, and although we have to rely on a relatively small number of data points, it is clear that 30 when a molecule that carries both an $-\mathrm{OH}$ group as well as a cyanooxime moiety is confronted with two hydrogen-bond acceptor sites of different strength, the outcome is likely to result in a hydrogen-bond between the $-\mathrm{OH}$ moiety and the best acceptor site, leaving the cyanooxime to bind to the second-best 35 acceptor. It should also be pointed out that hydrogen bonds, even though they have considerable strength and directionality, are relatively weak and reversible, which means that synthon polymorphism ${ }^{20}$ and synthon crossover ${ }^{21}$ is always a possibility in crystal engineering. However, even though exceptions are to be 40 expected, it is still of considerable value to be able to identify patterns of behaviour as such trends provide excellent starting points for further studies that can validate or refine early observations.

\section{${ }_{45}$ Synthesis of (Z)-N,4-dihydroxybenzimidoyl cyanide, $\mathrm{PhOx}$}

$10 \mathrm{~g}$ of $\mathrm{NaOH}$ was dissolved in $250 \mathrm{ml}$ of methanol. $2.0 \mathrm{~g}$ (15.0 mmol) of 2-(4-hydroxyphenyl)acetonitrile was dissolved in $50 \mathrm{ml}$ of methanol and added to the $\mathrm{NaOH}$ solution and allowed to stir for 1 hour. Methyl nitrite was bubbled through the solution 50 over 30 minutes. The resulting solution was allowed to stir at room temperature for 48 hours. Methanol was removed under reduced pressure and the remaining solid was dissolved in $100 \mathrm{ml}$ of water and cooled in an ice bath. The $\mathrm{pH}$ was then slowly lowered to $\mathrm{pH}=2$ with $6 \mathrm{M} \mathrm{HCl}$. The precipitate was filtered off 55 and washed with ice water. $1.58 \mathrm{~g}$ of pure product was obtained. (Yield 65\%) M.p.: $160-165{ }^{\circ} \mathrm{C}{ }^{1} \mathrm{H}$ NMR (400 MHz, DMSO- $\left.d_{6}\right) \delta$ ppm 6.89 (d, $J=8.59 \mathrm{~Hz}, 2 \mathrm{H}) 7.55$ (d, J=8.98 Hz, $2 \mathrm{H}$ ) 10.13 (br. s., 1 H) 13.29 (br. s., 1 H)
60

\section{Acknowledgments}

We are grateful for financial support from NSF (CHE0957607) and from the Johnson Center for Basic Cancer Research.

\section{${ }_{65}$ Notes and references}

${ }^{a}$ Kansas State University, Department of Chemistry, 213 CBC Building, Manhattan, KS 66506-0401, USA. Fax: 1-785-532 6666; Tel: 1-785-532 6096; E-mail: aakeroy@ksu.edu

$70 †$ Electronic Supplementary Information (ESI) available: CCDC 910341910345, synthesis and characterization of 1-8.]. See DOI: $10.1039 / \mathrm{b} 000000 \mathrm{x} /$

${ }^{1}$ A. Atria, M. Michael, Pharmazie, 1982, 37, 551-553

${ }^{2}$ M. Kato, S. Nishino, M. Ohno, S. Fukuyama, Y. Kita, Y. Hirasawa, and Y. Nakanishi, H. Takasugi, K. Sakane, Bioorg. Med. Chem. Lett., 1996, 6, 33-38

${ }^{3}$ Nakayama, A.; Iwamura, H.; Niwa, A.; Nakagawa, and Y.; Fujita, J. Agric. Food Chem. 1985, 33, 1034-1041

${ }^{4}$ C. B. Aakeröy, A. M. Beatty and D. S. Leinen, CrystEngComm, 2002, 4, 310-314

${ }^{5}$ H. Iwamura J. Med. Chem., 1980, 23, 308-312

${ }^{6}$ E. A. Bruton, L. Brammer, C. F. Pigge, C. B. Aakeröy, and D. S. Leinen, New J. Chem., 2003, 27, 1084; C.B. Aakeröy, A.S. Sinha, K.N. Epa, P.D. Chopade, M.M. Smith, and J. Desper, Cryst. Growth\&Des., http://dx.doi.org/10.1021/cg4005246, .

7 N. Gerasimchuk, A.N. Esaulenko, K. N. Dalley and C. Moore, Dalton, 2010, 39, 749 .

${ }^{8}$ C. A. Hunter, Angew. Chem. Int. Ed. 2004, 43, 5310-5324.

${ }^{9}$ D. Musumeci, C. A. Hunter, R. Prohens, S. Scuderi and J. F. McCabe, Chem. Sci., 2011, 2, 883-890.

${ }^{10}$ C. B. Aakeröy, D. J. Salmon , M. M. Smith , and J. Desper Crystal Growth \& Design, 2006, 6, 4, 1033-1042

${ }^{11}$ L. R. MacGillivray, J. L. Reid and J. A. Ripmeester, J. Am. Chem. Soc., 2000, 122, 7817

${ }^{12}$ K. S. Huang, D. Britton, M. C. Etter and S. R. Byrn, J. Mater. Chem., $1997,7,713$

13 D. Y. Lee, N. Singh, A. Satyender, and D. O. Jang, Tetrahedron Letters, 2011, 52, 51, 6919-6922

14 K. Biradha and R. Santra, Chem. Soc. Rev., 2013,42, 950-967; C.B. Aakeröy, N.R. Champness and C. Janiak, CrystEngComm, 2010,12, 22-43

15 C. B. Aakeröy, J. Desper, and M. M. Smith, Chem. Commun. 2007, 3936-3938

16 T. R.Shattock, K. K.Arora, P.Vishweshwar, M.J.Zaworotko, Cryst.Growth Des, 2008, 8, 4533

17 M. C. Etter, J. Phys. Chem. 1991, 95, 4601.

18 C. B. Aakeröy, J. Desper and J. F. Urbina, Chem. Commun., 2005, 2820-2822.

19 Calculated using Advanced Chemistry Development (ACD/Labs) Software V11.02 (C) 1994-2012 ACD/Labs)

20 A. Mukherjee and G. R. Desiraju. Chem. Commun., 2011, 47, 40904092; B. Sarma, P. Sanphui and A. Nangia, , Cryst. Growth \& Des. 2010, 10, 2388.

21 C. B. Aakeröy, P. D. Chopade, and J. Desper, Cryst. Growth Des., 2011, 11, 5333-5336. 